\title{
Liver disease after bone marrow transplantation
}

\author{
M J G FARTHING*, M L CLARK, J P SLOANE, \\ $R$ L POWLES, and T J McELWAIN \\ From the Department of Gastroenterology, St Bartholomew's Hospital, London, and the Leukaemia Unit, \\ The Royal Marsden Hospital, Sutton, Surrey
}

SUMMARY Liver dysfunction occurs after bone marrow transplantation but the relative importance of graft versus host disease and other factors, such as infection, radiation, and drugs, has not been clearly established. We have studied liver status before and after bone marrow transplantation in 43 consecutive patients and have related this to survival and factors that are recognised to cause liver injury. Minor abnormalities of liver tests occurred in $21 \%$ of patients before grafting but this did not influence survival or the development of liver disease after transplantation. During the first 50 days after grafting, $83 \%$ of patients had abnormal liver tests which were more severe in patients who subsequently died. Alanine transaminase was significantly higher in non-survivors and appeared to predict survival early after transplantation. Only non-survivors developed clinical signs of liver disease. Severe liver disease was always associated with graft versus host disease and atypia of the small bile ducts was the most useful histological marker of hepatic involvement with this disease. Two of the patients with hepatic graft versus host disease also had hepatic veno-occlusive disease and three fatalities had opportunistic infection of the liver, although, in the latter, death was not due primarily to liver dysfunction. Previous hepatitis and androgen therapy could not be implicated as important causes of hepatic damage but chemotherapy for acute leukaemia and conditioning regimens for bone marrow transplanatation appear to be the most important factors in the development of hepatic veno-occlusive disease.

Hepatic dysfunction is a well-recognised feature of graft versus host disease (GVHD) complicating bone marrow transplantation ${ }^{1-3}$ and usually occurs when there is already skin or gut involvement. GVHD can occur in up to $70 \%$ of successful allogeneic grafts ${ }^{2} 45$ and now accounts for many of the deaths after grafts for acute leukaemia. The development of severe liver disease has been reported ${ }^{6}{ }^{7}$ but its prevalence and effect on survival remain uncertain. Hepatic dysfunction after bone marrow grafting is often attributed to GVHD but many other factors, such as previous hepatitis, chemotherapy, radiation, opportunistic infection, and drugs used to treat GVHD, are also likely to be important. Severe distrubance of liver function has commonly been associated with death after bone marrow transplantation at the Royal Marsden Unit and we have therefore made a retrospective study of

\footnotetext{
* Address for correspondence: Dr M J G Farthing, Division of Geographic Medicine, Tufts University School of Medicine, Box 22, 136 Harrison Avenue, Boston, MA 02111, USA.

Received for publication 28 August 1981
}

liver function before and after bone marrow grafting. We have examined the relationship between GVHD and other possible aetiological factors and searched for markers that might predict survival and the development of liver disease.

\section{Methods}

\section{PATIENTS}

Forty consecutive patients, 14 with aplastic anaemia, 21 with acute leukaemia and two with disseminated malignancy received allogeneic bone marrow transplants from HLA identical and mixedlymphocyte-culture compatible siblings, and three patients with acute leukaemia (nos. 31,32 , and 41 ) received syngeneic marrow from an identical twin.

Bone marrow transplantation was performed according to the Seattle schedule. ${ }^{8}$ Five days before grafting the donor buffy coat was given, followed in patients with leukaemia and other neoplastic disease by cyclophosphamide, $65 \mathrm{mg} / \mathrm{kg}$ for the next two days. Thirty-six hours later these patients were given 1000 rads total body irradiation as a single fraction 
from a cobalt source at $2.5 \mathrm{rad} / \mathrm{min}$, after which bone marrow was infused intravenously. Patients grafted for aplastic anaemia were treated similarly, except that cyclophosphamide was given at $60 \mathrm{mg} / \mathrm{kg}$ for four days and they did not receive total body irradiation. On the day after transplantation oral methotrexate ${ }^{29}$ or cyclosporin $A^{10}$ or both were given as a prophylaxis against GVHD. After transplantation patients were nursed in reverse barrier isolation, ate sterile food, and received oral nonadsorbable antibiotics. ${ }^{11}$ All transfused blood products were irradiated to 1500 rads. Clinical details with respect to age, initial diagnosis, previous chemotherapy and total body irradiation, GVHD, and liver histopathology are outlined in Tables 1 and 2.

\section{CLINICAL AND BIOCHEMICAL ASSESSMENT OF LIVER STATUS}

A clinical history was taken with particular emphasis on drugs and previous hepatic disorders, particularly hepatitis. Overall liver status was assessed by a combined clinical and biochemical grading system, the details of which are shown in Table 3. This was used to assess liver status before grafting and during an early ( $<50$ days) and a late ( $>50$ days) period after grafting. Alanine transaminase (ALT 'optimised' UV system, Boehringer Corporation,
London), alkaline phosphatase (Technicon autoanalyser II technique), and bilirubin (by autoanalyser using a standard alkaline diazo-coupling method) were measured regularly before transplantation, daily for at least three weeks after transplantation, and then at least weekly thereafter. Serum was tested for the presence of $\mathrm{HbsAg}$ (Hepatest, Burroughs Wellcome) and also, when appropriate, for antibodies to a variety of pathogens.

\section{HISTOPATHOLOGICAL ASSESSMENT OF LIVER}

Post mortem examinations were carried out in 17 of the 23 patients who died, which provided material for histological examination by conventional light microscopy. In addition, liver obtained by percutaneous biopsy was available in three survivors. Gram stains were used for the identification of bacteria and Grocott methanamine silver for fungi in the liver sections.

\section{DEFINITION OF GVHD}

Graft versus host disease was considered present if the characteristic erythematous and desquamative skin rash was accompanied by at least grade 2 histological changes in the skin. ${ }^{12}$ Diarrhoea and typical histological abnormalities in the rectal mucosa ${ }^{13}$ were taken as evidence of GVHD

Table 1 Survivors of bone marrow transplantation

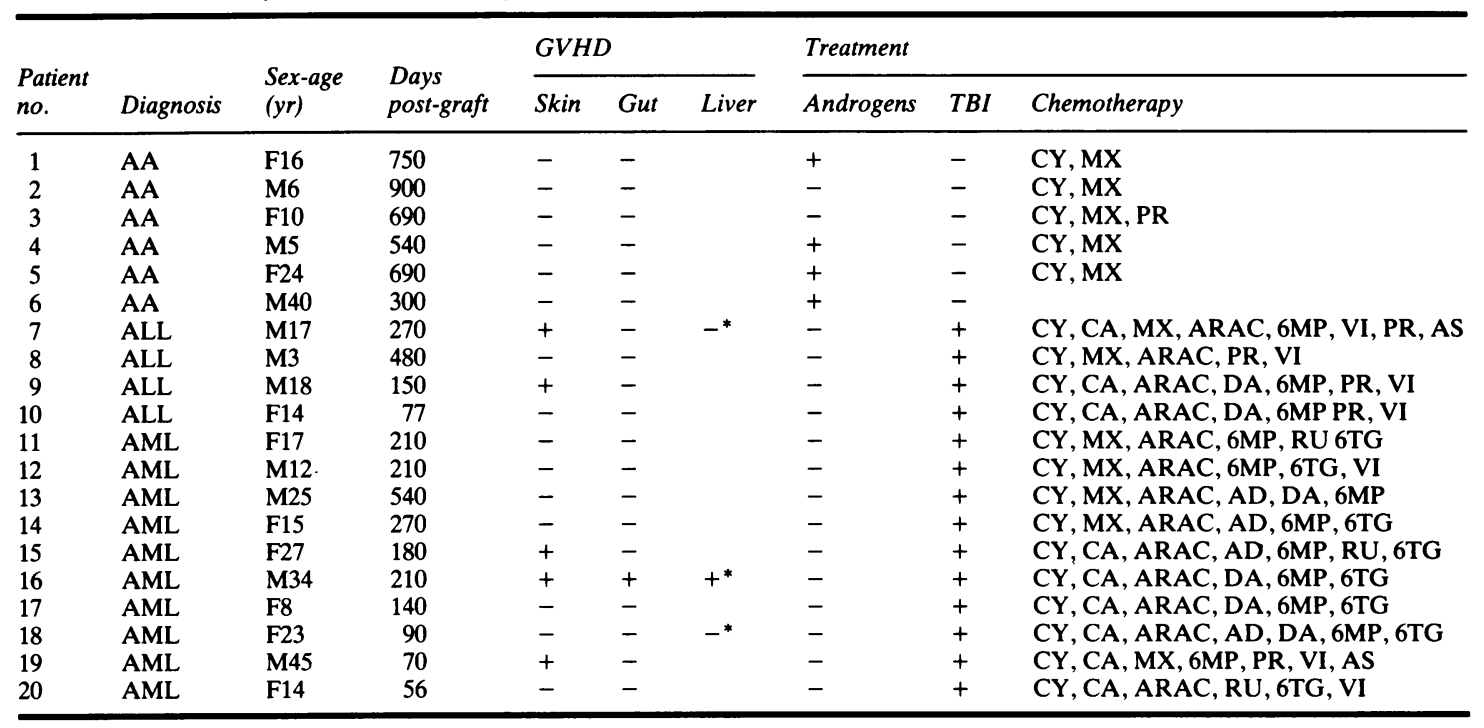

AA: aplastic anaemia. ALL: acute lymphoblastic leukaemia. AML: acute myeloid leukaemia. TBI: total body irradiation. CY: cyclophosphamide. MX: methotrexate. PR: prednisolone. CA: cyclosporin A. ARAC: cytosine arabinoside. VI: vincristine. 6MP: 6-mercaptopurine. DA: daunorubicin. AD: adriamycin. 6TG: 6-thioguanine. RU: rubidomycin. AS: asparaginase.

${ }^{*}$ Liver tissue obtained by needle biopsy available for histological examination. Patient 16 had the bile duct lesions of GVHD, but the others had no abnormality. 


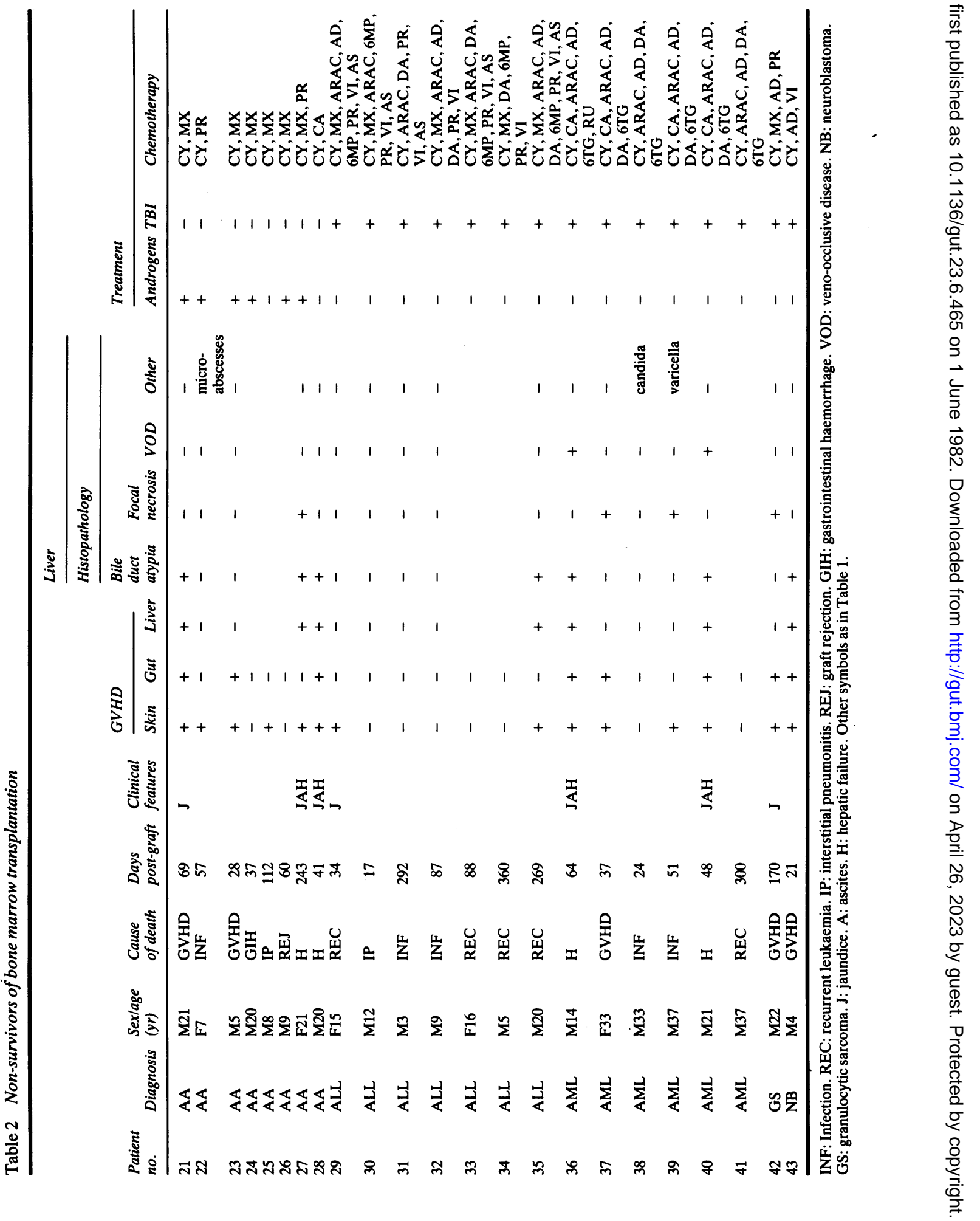


Table 3 Biochemical and clinical grading of liver status

\begin{tabular}{|c|c|c|c|c|}
\hline Grade & $\begin{array}{l}\text { Alanine } \\
\text { transaminase } \\
\text { (IU/l) }\end{array}$ & $\begin{array}{l}\text { Alkaline } \\
\text { phosphatase } \\
\text { (IU/l) }\end{array}$ & $\begin{array}{l}\text { Bilirubin } \\
(\mu \mathrm{mol} / \mathrm{l})\end{array}$ & $\begin{array}{l}\text { Clinical } \\
\text { signs }\end{array}$ \\
\hline 0 & Normal & Normal & Normal & None \\
\hline I & $21-100$ & $100-300$ & Normal & None \\
\hline II & $>100$ & $>300$ & Normal & None \\
\hline III & $>100$ & $>300$ & $13-30$ & None \\
\hline IV & $>100$ & $>300$ & $>30$ & $\begin{array}{l}\text { Jaundice, } \\
\text { ascites, } \\
\text { Liver failure }\end{array}$ \\
\hline $\begin{array}{l}\text { Normal } \\
\text { range }\end{array}$ & $<21$ & $<100$ & $<13$ & \\
\hline
\end{tabular}

involvement of the gastrointestinal tract. The diagnosis of hepatic GVHD was based solely on the histological findings of bile duct atypia with or without hepatocellular necrosis.

\section{Results}

SURVIVAL, GVHD, AND LIVER DISEASE AFTER

BONE MARROW TRANSPLANTATION

Of the first 43 patients grafted, 20 are alive with median survival times of 21 months, eight months, and six months for patients grafted for aplastic anaemia, acute myeloid leukaemia, and acute lymphoblastic leukaemia respectively. These same diagnostic groups have plateaux of survival extending to longer than three years, two years, and 1.5 years respectively. GVHD was observed in 19 of the 40 patients who received allogeneic grafts and in 14 of the 20 patients who died $(70 \%)$. The occurrence of the clinical signs of liver disease and GVHD and their relationship to survival in individual patients are shown in Tables 1 and 2 .

\section{LIVER STATUS BEFORE BONE MARROW TRANSPLANTATION \\ Previous hepatitis}

Aplastic anaemia followed acute hepatitis in three of the patients who subsequently received bone marrow transplants (nos. 1, 21, and 28), one of whom was $\mathrm{HbsAg}$ positive (no. 28). Other serological markers of acute hepatitis were not determined. Two of these patients (including the one who was HbsAg positive) died with severe GVHD with obvious hepatic involvement (nos. 21 and 28); the third is alive after a successful, uncomplicated graft. Another patient with acute myeloid leukaemia (no. 40) had $\mathrm{HbsAg}$ negative hepatitis during remission on maintenance chemotherapy one year before grafting. Liver tests at the time of grafting were normal but he died 47 days later with severe GVHD with liver involvement.

\section{Liver tests}

A rise in ALT (always less than $100 \mathrm{IU} / \mathrm{l}$ ) occurred in only nine of the 43 patients grafted, and was not associated with any abnormality of bilirubin or alkaline phosphatase. Abnormalities of ALT could not be related to any particular chemotherapeutic regimen and bore no relationship to survival or to the development of liver disease after bone marrow transplantation.

\section{LIVER STATUS AFTER BONE MARROW \\ TRANSPLANTATION}

Liver status during the early and late posttransplantation periods is shown for both survivors and non-survivors in Fig. 1. During the first 50 days after grafting, disturbance of liver tests occurred in $83 \%$ of patients. During this early period, differences were apparent between survivors and non-survivors. Forty per cent of the non-survivors had moderate to severe (grade II-IV) liver dysfunction compared with $18 \%$ of the survivors, none of whom had developed clinical signs of liver disease (grade IV).

In the later period ( $>50$ days) after bone marrow transplantation this pattern persisted: $56 \%$ of the non-survivors had grade II-IV hepatic dysfunction compared with $12 \%$ of the survivors (grade II and III only). To examine the relationship between abnormalities of liver tests and survival after grafting we analysed serial estimations of bilirubin, ALT, and alkaline phosphatase during the first 100 days. Hyperbilirubinaemia above $30 \mu \mathrm{mol} / 1$ occurred only in non-survivors. Median alkaline phosphatase tended to rise throughout this period (Fig. 2) but differences between survivors and non-survivors at $10,20,50$, and 100 days were not significant. Median values' for ALT were greater in nonsurvivors at 20 days after grafting and by $\mathbf{5 0}$ days this difference was significant (survivors, median 24 IU/1, range 9-130; non-survivors, median 69 IU/1, range 16-550; Mann Whitney $U$ test, $p<0.02$ ). Additional examination of these data showed that, if the ALT was abnormal at 20 days after grafting, the chance of long-term survival was only $25 \%$.

\section{PREVIOUS DRUG THERAPY}

We found no relation between previous androgen/ anabolic steroid therapy and survival or the likelihood of developing liver disease after transplantation. In addition, there was no correlation between the intensity of pre-graft chemotherapy and the development of liver disease after grafting.

OPPORTUNISTIC INFECTION AND LIVER DISEASE AFTER BONE MARROW TRANSPLANTATION Three of the 23 patients who died (13\%) had 


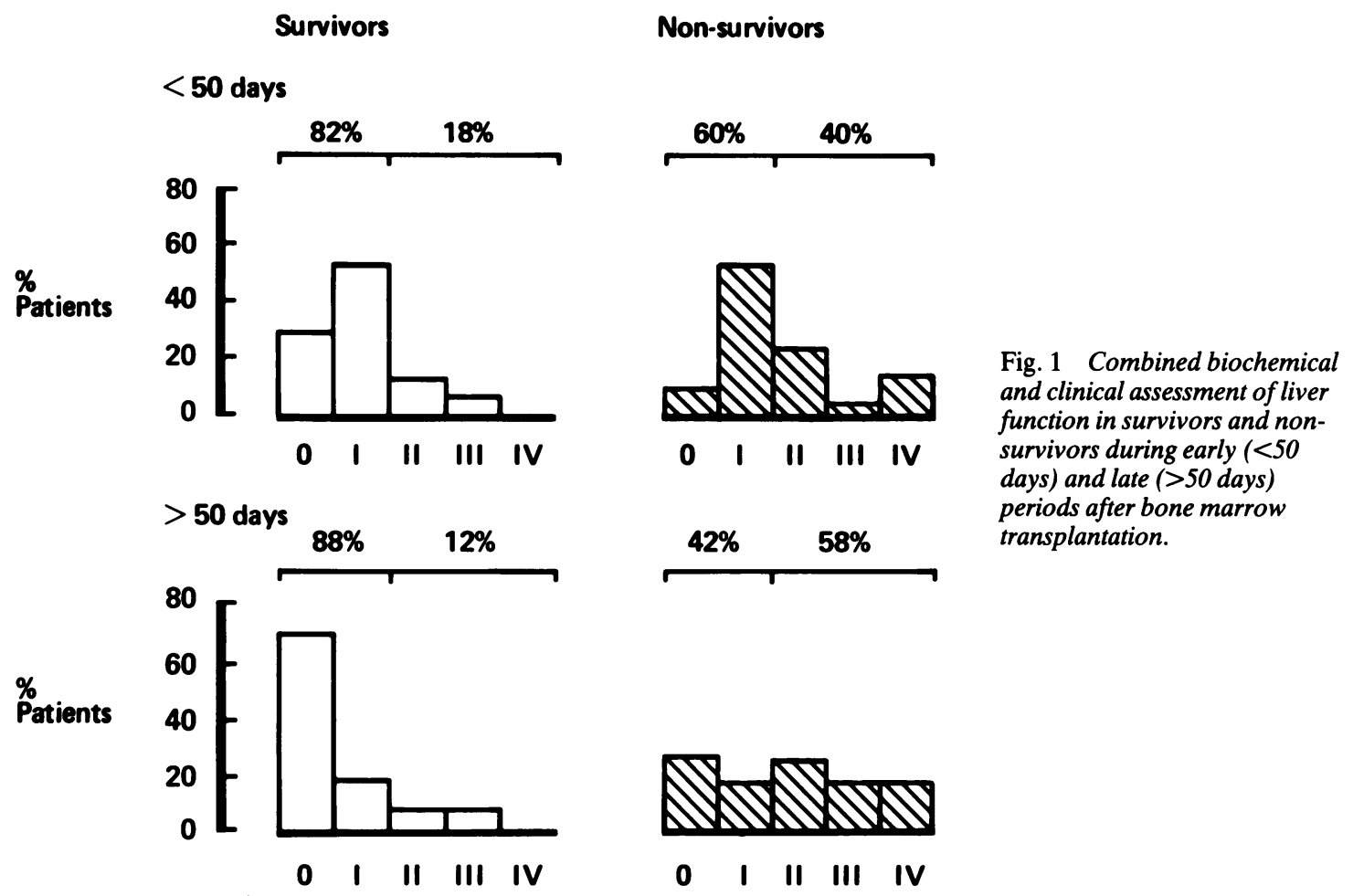

unequivocal histological evidence of opportunistic infection involving the liver (Table 2). One had varicella hepatitis, a second was found to have hepatic micro-abscesses containing Candida species, and the third had unspecified Gram-positive bacilli within the liver sinusoids. Despite these necropsy findings in the liver, all of these patients had disseminated disease and were thought to have died from the effects of overwhelming sepsis rather than liver failure. A fourth patient (no. 27) with mild skin GVHD, became jaundiced, developed clinical signs of liver failure, and had a rising titre to Toxoplasma gondii. However, the organism was not cultured before or after death, nor was it detected histologically in the liver. The significance of this rising titre remains uncertain, although the specific IgM titre also increased suggesting that there was recent infection.

\section{HISTOPATHOLOGICAL ASSESSMENT OF LIVER} AFTER BONE MARROW TRANSPLANTATION The histopathological features of the 17 livers obtained at necropsy, together with percutaneous liver biopsies in three survivors have already been described in detail ${ }^{10}$ but are summarised in Tables 1 and 2.

Atypia of the bile duct epithelium (Fig. 3) was present in eight patients and involved only small bile ducts. All of these patients had histological evidence of moderate to severe GVHD in the skin or gut, or both. In all but the mildest case, this bile duct lesion was associated with histological evidence of cholestasis, a mild lymphocytic infiltration, and a rise in serum alkaline phosphatase, although the latter was not significantly higher than in those patients without bile duct atypia. Four of these patients with bile duct atypia also had evidence of portal fibrosis. Focal hepatocyte necrosis was found in only four patients and in all cases the lesion was minor. In only one patient did it occur in association with the bile duct lesion. All the livers examined had evidence of moderate to severe siderosis.

Evidence of veno-occlusive disease (Fig. 4) was found in two patients (nos. 36 and 40), both of whom were jaundiced by the 20th day after transplantation and had other liver test abnormalities. At this time one had evidence of skin GVHD, as did the other within a further five days. Both subsequently developed oedema, ascites, and hypoalbuminaemia, and died in hepatic failure. Both of these patients had received a variety of chemotherapeutic agents including cytosine arabinoside, 6thioguanine, and adriamycin, both had severe GVHD, and both had had total body irradiation. 

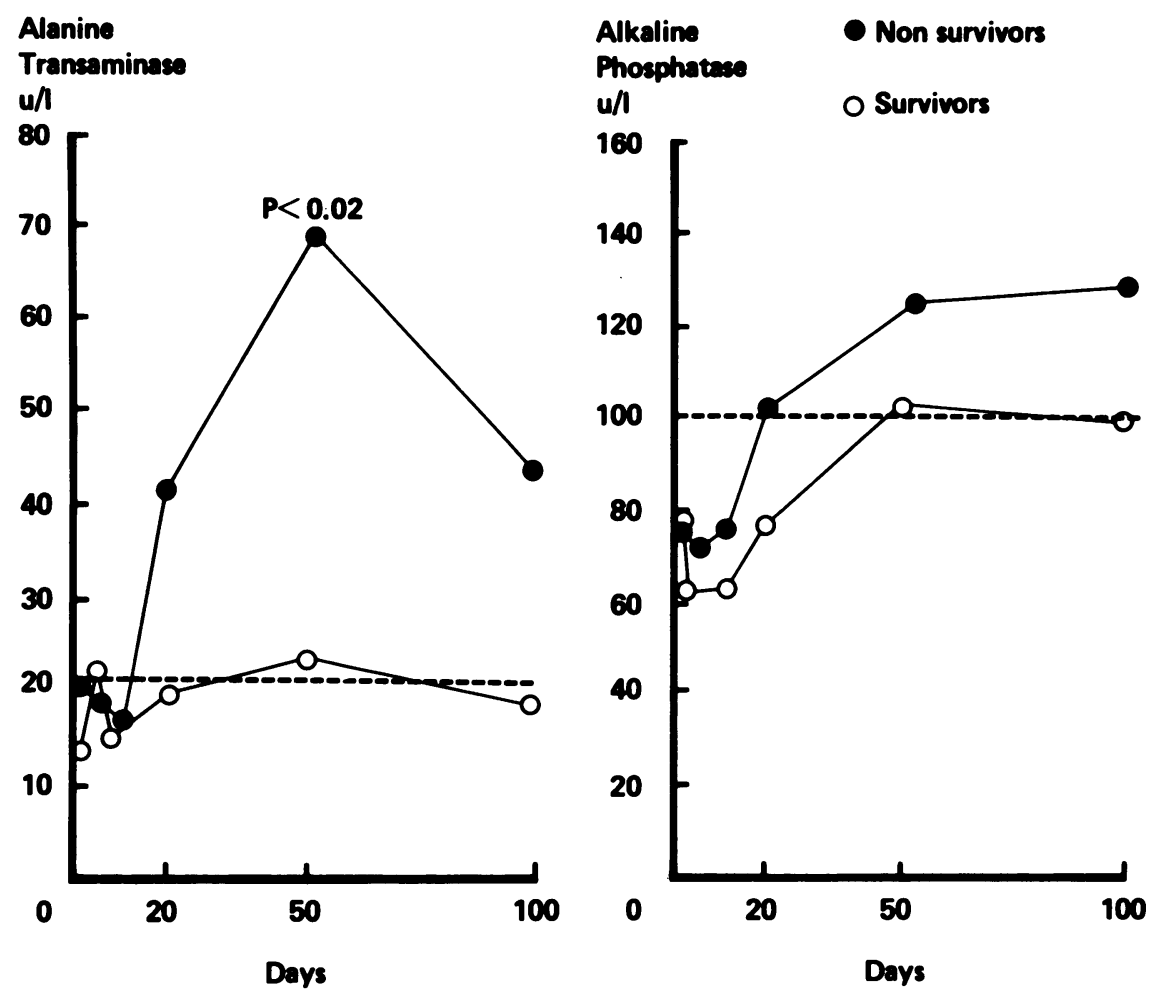

Fig. 2 Median alanine transaminase and alkaline phosphatase in survivors and non-survivors during the first 100 days after bone marrow transplantation.

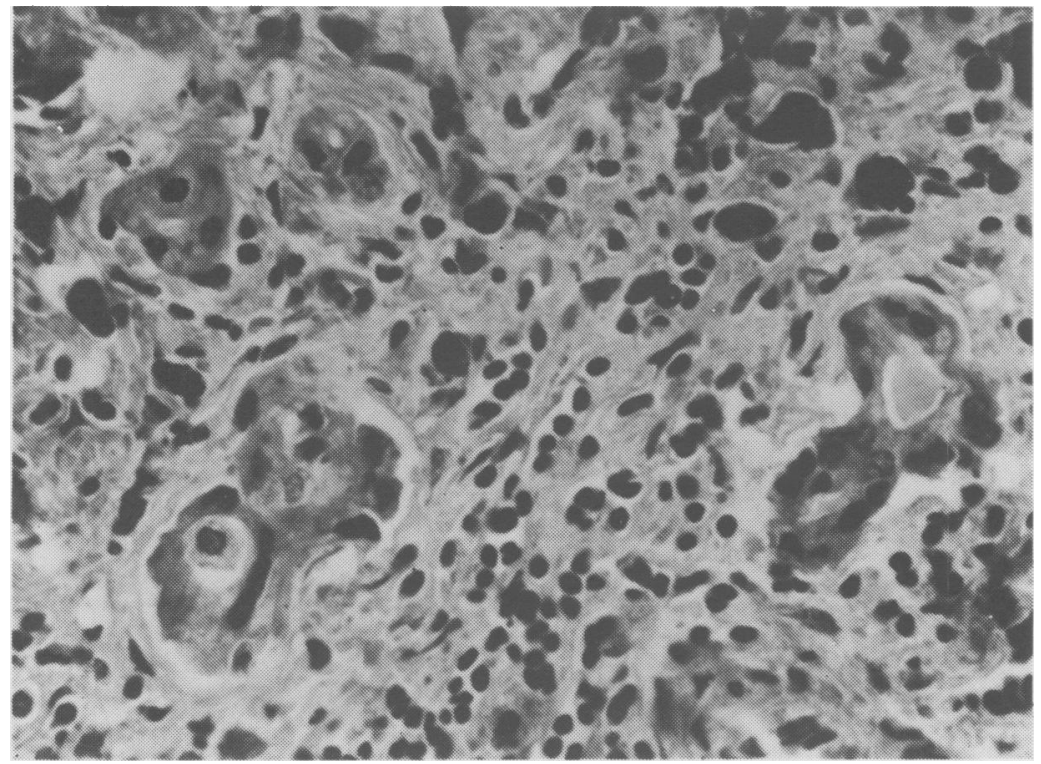

Fig. 3 Bile duct atypia. Small bile ducts showing epithelial atypia surrounded by a few chronic inflammatory cells and several large irregular clumps of haemosiderin. Haematoxylin and eosin stain, $\times 500$ (original magnification). 


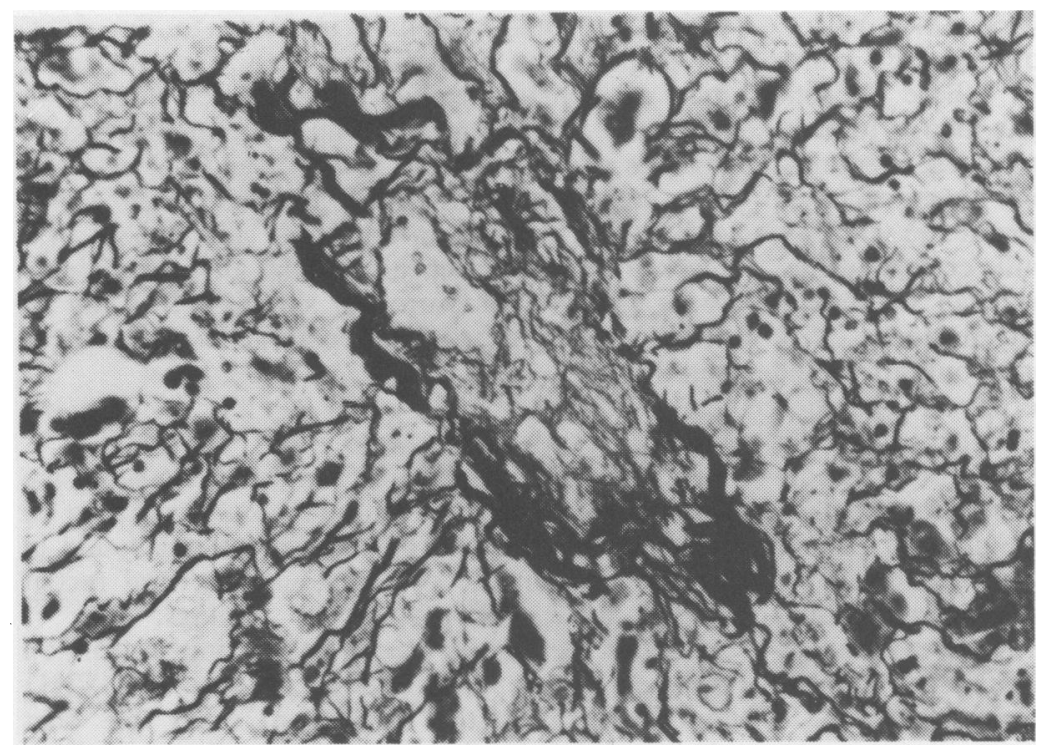

Fig. 4 Veno-occlusive disease. Central vein partially occluded by a fine meshwork of reticulin fibres. Reticulin stain, $\times 300$ (original magnification).

Minor abnormalities in reticulin pattern were observed in 16 patients and in six (nos. 21, 23, 28, 38,42 , and 43 ) it was particularly evident around the central veins.

\section{Discussion}

In the present study severe liver dysfunction occurred in seven of the 23 patients who died $(30 \%)$ and in all of these the disturbance of liver function was thought to be either the cause or a major contributor to death. The prevalence is similar to that reported previously when nine of the $29(31 \%)$ patients who died after bone marrow transplantation for aplastic anaemia had evidence of liver dysfunction, ${ }^{15}$ one of whom was thought to have chronic aggressive hepatitis and the remainder GVHD involvement of the liver. The clinical state of these patients and the histological criteria for making the diagnosis of hepatic GVHD were not reported. Our retrospective study demonstrates that, during the first 50 days after grafting, mild disturbances of liver tests occur in the majority of patients but in survivors were limited to rises in ALT and alkaline phosphatase, whereas significant hyperbilirubinaemia above $30 \mu \mathrm{mol} / \mathrm{l}$ was seen only in the non-survivors. During the later period after grafting ( $>50$ days), liver tests tended to improve in survivors, whereas in non-survivors they deteriorated: $58 \%$ had moderate to severe liver dysfunction. Although we are reluctant to place undue emphasis on these liver tests, the proposal arising from this study - that abnormalities of the ALT may predict survival after bone marrow transplantation as early as 20 days after grafting-requires prospective evaluation.

While the aetiology of this abnormality is likely to be multifactorial, it does suggest that factors other than the bile duct disturbance of GVHD contribute to transplantation liver injury.

PRE-GRAFT DRUG THERAPY AND ACUTE HEPATITIS Although many of the drugs used to treat acute leukaemia have been shown to be hepatotoxic, ${ }^{16}$ we were unable to find a relationship between the type or the extent of pre-graft chemotherapy and posttransplantation liver dysfunction. It is now apparent, however, that survival has been improved by grafting patients with acute myeloid leukaemia during their first remission. ${ }^{5} 17$ The reduced amount of chemotherapy that these patients have received may be an important factor in survival. Although 17 $\alpha$-alkylated androgenic and anabolic steroids are known to cause hepatic damage, ${ }^{18}{ }^{19}$ we found no correlation between previous androgen therapy and either survival or the propensity to develop liver dysfunction after grafting.

The effect of previous hepatitis on survival in the present study cannot be evaluated satisfactorily because of inadequate numbers of patients. However, it may be worth commenting that two of our three patients with post-hepatic aplastic anaemia died after grafting with severe hepatic GVHD and four of six patients with the same initial diagnosis in Seattle died, two of whom had liver complications. ${ }^{15}$ 
CONDITIONING REGIMEN FOR BONE MARROW Although high-dose cyclophosphamide causes hepatic damage in animals, ${ }^{20} 2 \mathrm{f}$ there is little evidence of severe hepatotoxicity in man. ${ }^{22}$ Ionising radiation, however, is known to cause hepatitis, hepatic fibrosis, ${ }^{23}{ }^{24}$ and hepatic veno-occlusive disease..$^{25}$ In addition, hepatic tolerance to radiation is reduced when combined with certain drugs, particularly adriamycin, ${ }^{26}$ antinomycin $\mathrm{D}$, and 5 fluoro-uracil. ${ }^{27}$ However, our patients with leukaemia received the same conditioning regimen so the specific effects of chemotherapy and radiation cannot be determined, but a recent study ${ }^{6}$ has demonstrated increased hepatotoxicity of conditioning regimens which included carmustine and busulfan. In our study, the prevalence of clinical liver disease was not significantly reduced in patients grafted for aplastic anaemia (conditioned without total body irradiation), although a direct comparison cannot be made, as these patients received more prolonged conditioning with cyclophosphamide.

\section{GVHD}

GVHD occurred in $48 \%$ of the 40 patients who received allogeneic grafts and in $70 \%$ of the fatalities. Although there was a strong association between the occurrence of severe clinical liver disease and the presence of GVHD elsewhere, biochemical abnormalities were more common and occurred in $83 \%$ of the patients, suggesting that factors other than GVHD are responsible for hepatic dysfunction after bone marrow transplantation. The most striking histological feature in the liver associated with skin and gut GVHD was cellular atypia of small bile ducts which was almost invariably associated with cholestasis. This feature has been reported previously in man, ${ }^{3}{ }^{1328}$ and has been shown recently to be a reliable indicator of hepatic involvement by GVHD in the dog. ${ }^{29}$ These findings suggest that bile duct atypia is probably the most important single feature of hepatic GVHD and may also be a guide to its severity. ${ }^{13}$ There are previous reports both in animals ${ }^{29} 30$ and $\operatorname{man}^{163132}$ of focal necrosis occurring in the liver in GVHD but, in this study, it was seen infrequently and was always minor. Using the criterion of bile duct atypia, only seven of the 14 patients who died with GVHD were regarded as having hepatic GVHD, although all of the remainder had moderate to severe abnormalities of liver tests. We did not observe bile duct atypia in patients who did not have GVHD in another organ.

Methotrexate and cyclosporin $\mathrm{A}^{10}$ were used in prophylaxis and treatment of GVHD. Although methotrexate can cause liver damage ${ }^{33} 34$ we did not discover any obvious toxic effects in our patients which we could definitely attribute to the drug, although it may have contributed to the abnormalities of hepatic reticulin pattern seen in some patients. ${ }^{67}$ Cyclosporin A causes reversible abnormalities of liver tests in $\operatorname{man}^{10}{ }^{35}$ and animals and liver cell necrosis in the dog. ${ }^{36}$ Cyclosporin A was given to 12 patients in this study and the six who received it prophylactically are all alive. It appears to be effective in controlling skin GVHD ${ }^{10}$ but its effect on the liver and hepatic GVHD requires clarification.

VENO-OCCLUSIVE DISEASE

Histological evidence of hepatic veno-occlusive disease accompanied by the clinical syndrome of jaundice, ascites, and hepatic failure was found in two patients in the present study. Several recent studies have reported similar findings. ${ }^{6732} 3738$ Although Berk et al. ${ }^{32}$ found a striking association between hepatic VOD and the presence of GVHD in other organs, the absence of small bile duct abnormalities in their patients-a feature which $\mathrm{we}^{14}$ and others ${ }^{1329}$ now regard as indicative of hepatic GVHD-makes it difficult to be certain whether there was hepatic GVHD involvement in their patients. Both of our patients received total body irradiation which itself can cause venoocclusive disease, ${ }^{25}$ but hepatic veno-occlusive disease has now been described in patients conditioned without total body irradiation. ${ }^{32}$ Radiation, however, may be a contributory factor in the production of veno-occlusive disease in some recipients of bone marrow transplants. The development of veno-occlusive disease can clearly be independent of the presence of hepatic GVHD, as the former has occurred in patients grafted with autologous marrow. ${ }^{73}$ Current evidence indicates that veno-occlusive disease occurs more commonly in patients grafted for acute leukaemia, ${ }^{78}$ suggesting that chemotherapeutic agents have an important place in its pathogenesis. Shulman et al. ${ }^{7}$ have also shown a significantly increased prevalence of veno-occlusive disease in patients who received more intensive chemotherapy and in those whose conditioning included dimethyl busulfan. Analysis of the current literature on veno-occlusive disease after bone marrow transplantation suggests that the antimetabolites cytosine arabinoside and 6-thioguanine are the drugs most commonly associated with this disease, ${ }^{38}$ both of which were among the drugs received by our patients.

Liver dysfunction after bone marrow transplantation is common and clearly a complex matter and it is unlikely that any single factor is responsible. Severe liver disease after bone marrow transplantation, however, was always associated with 
GVHD alone or in combination with veno-occlusive disease. It would seem important that histological diagnostic criteria are established for hepatic GVHD and current $\epsilon$ vidence would favour bile duct atypia as the most useful. Liver test abnormality alone is insufficient to make a diagnosis of hepatic GVHD.

Drugs, radiation, or opportunistic infection can be important in some patients either alone or in combination. The cause of hepatic veno-occlusive disease and the abnormalities of hepatic reticulin remains uncertain, although chemotherapy for acute leukaemia and pre-graft conditioning regimens appear at present to be the most important factors.

\section{References}

1 Kruger GRF, Berard CW, DeLellis RA et al. Graftversus-host disease. Am J Pathol 1971; 63: 179-201.

2 Thomas ED, Storb R, Clift RA et al. Bone marrow transplantation (second of two parts). $N$ Engl J Med 1975; 292: 895-902.

3 Woodruff JM, Hansen JA, Good RA et al. The pathology of graft-versus-host reaction (GVHR) in adults receiving bone marrow transplants. Transplant Proc 1976; 8: 675-84.

4 Storb R, Prentice RL, Thomas ED. Treatment of aplastic anaemia by marrow transplantation from HLA identical siblings. Prognostic factors associated with graft versus host disease and survival. J Clin Invest 1977; 59: 625-32.

5 Thomas ED, Buckner CD, Clift RA et al. Marrow transplantation for acute nonlymphoblastic leukaemia in first remission. $N$ Engl J Med 1979; 301: 597-9.

6 Beschorner WE, Pino J, Boitnott JK, Tutschka PJ, Santos G. Pathology of the liver with bone marrow transplantation. Effects of busulfan, carmustine, acute graft-versus-host disease and cytomegalovirus infection. Am J Pathol 1980; 99: 369-85.

7 Shulman HM, McDonald GB, Matthews D, Doney KC, Kopecky KJ, Gauvreau JM, Thomas ED. An analysis of hepatic venocclusive disease and centrilobular hepatic degeneration following bone marrow transplantation. Gastroenterology 1980; 79: 1178-91.

8 Thomas ED, Buckner CD, Banaji $\mathrm{M}$ et al. One hundred patients with acute leukaemia treated by chemotherapy, total body irradiation and allogeneic bone marrow transplantation. Blood 1977; 49: 511-33.

9 Storb R, Epstein RB, Graham TC, Thomas ED. Methotrexate regimens for control of graft-versus-host disease in dogs with allogeneic marrow grafts. Transplantation 1970; 9: 240-6.

10 Powles RL, Clink H, Sloane J, Barrett AJ, Kay HEM, McElwain TJ. Cyclosporin A for the treatment of graft-versus-host disease in man. Lancet 1978; 2: 1327-31.

11 Storring RA, Jameson B, McElwain TJ, Wiltshaw E, Spiers ASD, Gaya H. Oral non-absorbed antibiotics prevent infection in acute non-lymphoblastic leukaemia. Läncet 1977; 2: 837-40.

12 Sale GE, Lerner KG, Barker EA, Shulman HM, Thomas ED. The skin biopsy in the diagnosis of acute graft-versus-host disease in man. Am J Pathol 1977; 89: 621-36.

13 Slavin RE, Santos GW. The graft versus host reaction in man after bone marrow transplantation: pathology, pathogenesis, clinical features and implication. Clin Immunol Immunopathol 1973; 1: 472-98.

14 Sloane JP, Farthing MJG, Powles RL. Histopathological changes in the liver following allogeneic bone marrow transplantation. J Clin Pathol 1980; 33: 344-50.

15 Storb R, Thomas ED, Weiden PL et al. Aplastic anaemia treated by allogeneic bone marrow transplantation: A report on 49 new cases from Seattle. Blood 1976; 48: 817-41.

16 Ludwig J. Drug effects on the liver. A tabular compilation of drugs and drug-related hepatic diseases. Dig Dis Sci 1979; 24: 785-96.

17 Powles RL, Clink HM, Bandini G et al. Bone marrow transplantation in acute myelogenous leukaemia. Lancet 1980; 1: 1047-50.

18 Bagheri SA, Boyer JL. Peliosis hepatitis associated with androgenic anabolic steroid therapy. A severe form of hepatic injury. Ann Intern Med 1974; 81: 610-8.

19 Westaby D, Paradinas FJ, Ogles J et al. Liver damage from long-term methyltestosterone. Lancet 1977; 2: 261-3.

20 Lee C, Castles TR, Kintner LD. Single dose toxicity of cyclophosphamide (NSC-26271) in dogs and monkeys. Cancer Chemother Rep 1973; Pt 3, 4: 51-76.

21 Celle G, Dodero M, Bogliolo G et al. Chronic treatment with azathioprine and cyclophosphamide in rats: Structural and functional effects on small intestine and liver. GEN 1977; 31: 179-84.

22 Aubrey DA. Massive hepatic necrosis after cyclophosphamide. $\mathrm{Br}$ Med J 1970; 2: 588.

23 Lansing AM, Davis WM, Brizel HE. Radiation hepatitis. Arch Surg 1968; 96: 878-82.

24 Lewin K, Millis RR. Human radiation hepatitis. Arch Pathol 1973; 96: 21-6.

25 Reed GB, Cox AJ. The human liver after radiation injury. Am J Pathol 1966; 48: 597-611.

26 Kun LE, Camitta BM. Hepatopathy following irradiation and adriamycin. Cancer 1978; 42: 81-4.

27 Tefft M, Mitus A, Jaffe N. Irradiation of the liver in children: acute effects enhanced by concomitant chemotherapeutic administration. AJR 1971; 111: 16573.

28 Lerner KG, Kao GF, Storb R et al. Histopathology of graft versus host reaction (GVHR) in human recipients of marrow from HL-A matched sibling donors. Transplant Proc 1974; 6: 367-71.

29 Sale GE, Storb R, Kolb H. Histopathology of acute graft-versus-host disease in the dog. Transplantation 1978; 26: 103-6.

30 Van Bekkum DW, De Vries MJ. Radiation chimeras. New York: Academic Press, 1967.

31 Slavin RE, Woodruff JM. Pathology of bone marrow transplantation. Pathol Ann 1974; 9: 291-344.

32 Berk PD, Popper H, Kruger GRF, Decter J, Herzig G, 
Graw RG. Veno-occlusive disease of the liver after allogeneic bone marrow transplantation. Ann Intern Med 1979; 90: 158-64.

33 Dahl MGC, Gregory MM, Scheuer PJ. Liver damage due to methotrexate in patients with psoriasis. $\mathrm{Br}$ Med J 1971; 1: 625-30.

34 Dahl MGC, Gregory MM, Scheuer PJ. Methotrexate hepatotoxicity in psoriasis - comparison of different dose regimens. $\mathrm{Br}$ Med J 1972; 1 : 654.

35 Calne RY, Thiru S, McMaster Pet al. Cyclosporin A in patients receiving renal allografts from cadaver donors. Lancet 1978; 2: 1324-7.

36 Calne RY. White JG, Pentlow BD et al. Cyclosporin
A: Preliminary observations in dogs with pancreatic duodenal allografts and patients with cadaveric renal transplants. Transplant Proc 1979; 11: 860-4.

37 Jacobs P, Miller JL, Uys CJ, Dietrich BE. Fatal veno-occlusive disease of the liver after chemotherapy, whole body irradiation and bone marrow transplantation for refractory acute leukaemia. S Afr Med J 1979; 55: 5-10.

38 Woods WG, Dehner LP, Nesbit ME, Krivit W, Coccia PF, Ramsay NKC, Kim TH, Kersey JH. Fatal venoocclusive disease of the liver following high dose chemotherapy, irradiation and bone marrow transplantation. Am J Med 1980; 68: 285-90. 